\title{
Forthcoming ...
}

\author{
Journal of Anthropological Research, Vol. 62(3), Fall 2006) \\ For access after publication, please see JAR Online at: \\ http://ets.umdl.umich.edu/j/jar/
}

\section{Grey Suit or Brown Carhartt: Narrative Transition, Relocation and Reorientation in the Lives of Corporate Refugees}

\begin{abstract}
This article examines relocation stories of people who leave behind corporate work culture, relocate from metropolitan areas to small towns and rural places and attempt to reorient themselves to work and family obligations. Decisions to start over take place within the context of moral questions about what makes a life worth living and what does not through a process in which geography has bearing. For these migrants, a choice about where to live is also one about how to live. Choices of how to live one's life are made of more than simple economics, they are also moral. The restructuring and corporate downsizing that defines the contemporary workplace has led some workers and their families to challenge assumptions of the American Dream that promises future reward for loyalty to an employer, hard work and self-sacrifice. These life-style migrants relocate in their attempt to find potential selves and idealized families in new places.
\end{abstract}

\section{KEYWORDS}

Post-industrial economic restructuring; career change; urban-to-rural migration; work and family studies; narrative analysis

Brian A. Hoey, Ph.D., Research Fellow

Center for the Ethnography of Everyday Life

University of Michigan

426 Thompson Street

Ann Arbor, MI 48106-1248

734-615-3536

734-615-3557 FAX

bhoey@umich.edu 